\title{
Action research in the physics classroom: the impact of authentic, inquiry based learning or instruction on the learning of thermal physics
}

Flavian Brian Fernandez ${ }^{1,2}$

Correspondence:

flavian_brian_fernandez@moe.edu.sg

'Singapore Ministry of Education, Singapore, Singapore

${ }^{2}$ Woodgrove Secondary School, 3 Woodlands Ave 6, Singapore

738990, Singapore

\begin{abstract}
Students experience thermal physics phenomena from a very young age, but in Singapore their formal science instruction occurs in Primary 3 or 4 (aged 9 or 10) and again in secondary school (aged 13 to 16). Hence, students often form alternative or incomplete scientific conceptions related to thermal physics well before they begin learning it in the science classroom. The team of teachers involved in this study, therefore, believed that traditional instruction would be largely ineffective because it does not take into account students' existing beliefs about thermal physics. An action research process was undertaken to investigate if a more interactive and engaging pedagogical approach, such as authentic, inquiry based learning, could make students' thinking more explicit through discussions and other social interactions. Three intact classes of Secondary-3 students were selected: a high-performing control group and a low-performing control group using Traditional Physics Instruction (TPI) and an experimental group using Authentic Inquiry-Based Instruction (AIBI). Students in the experimental group demonstrated significant gains in conceptual understanding and student self-efficacy, although students in the high-performing control group continued to outscore students in the experimental group. Further analysis of the data revealed a correlation between students' achievement on a standardised test and conceptual understanding of the subject matter in the AIBI classroom. Traditional forms of instruction are inadequate because they do little to develop students' self-efficacy and interest in the subject matter. More emphasis should be placed on embedding authentic and formative assessment tasks within the curriculum, rather than end-of-unit standardised tests.
\end{abstract}

Keywords: Science education, Authentic learning, Inquiry based learning, Conceptual understanding, Student achievement, Student self-efficacy

\section{Introduction}

Action research - as defined in this paper - refers to a formal, structured process in which teachers work collaboratively towards solving problems using research methodologies (Glanz, 2014; McNiff, 2013). Generally, teachers involved in action research engage in multiple cycles of plan-act-observe-reflect actions (Salleh, revised for resubmission), with each cycle informing the next and eventually leading to improved teaching and learning outcomes in the classroom. The reasons for action research being such a

(c) The Author(s). 2017 Open Access This article is distributed under the terms of the Creative Commons Attribution 4.0 International License (http://creativecommons.org/licenses/by/4.0/), which permits unrestricted use, distribution, and reproduction in any medium, provided you give appropriate credit to the original author(s) and the source, provide a link to the Creative Commons license, and indicate if changes were made. 
powerful and appealing tool for teachers are twofold. Firstly, it presents teachers with a systematic approach towards either crafting new curriculum or improving existing curriculum to better meet the needs of their specific student profile. Secondly, from the perspective of teacher professional development, it expands their capacity and develops their competence in enacting this new or improved curriculum in the classroom. This particular study was borne out of a collective belief among a team of physics teachers that traditional forms of instruction were not effective in achieving teaching and learning outcomes in thermal physics. They embarked on an action research process to investigate if a more engaging and interactive pedagogical approach - authentic, inquiry-based learning or instruction - could make students' thinking more explicit through discussions and other social interactions. The insights gleaned from students' existing conceptions would then inform the next phase of teaching and learning, making the entire process more effective and efficient.

Inquiry learning is a learner-centred pedagogy in which students play an active part in the process of knowledge discovery or acquisition. In recent years, a number of studies involving inquiry learning have reported its positive effects on science education (Fortus, Dershimer, Krajcik, Marx \& Mamlok-Naaman, 2004; Hmelo, Holton \& Kolodner, 2000). These include developing linguistic skills to explain scientific phenomena, achieving a complete and coherent understanding of complex phenomena and connecting science learning with the real world (Bouillion \& Gomez, 2001; Warren, Ballenger, Ogonowski, Rosebury, \& Hudcourt-Barnes, 2001). Most importantly however, the process of inquiry learning often requires a conceptual change in - and not simply an addition to - their existing understanding of everyday phenomena (Carey 2000).

While the positive effects of authentic, inquiry-based learning or instruction have been well-researched and documented there remains a lack of empirical studies to support such claims in the field of science education in Southeast Asia. One possible reason for this, as noted by Hallinger (2010), is that the cultural and institutional contexts of Southeast Asia vary sharply with those of Western societies. Rote-learning, teacher-directed instruction and highly centralized administrative procedures are reflective of a compliant society in which 'teachers dispense truth, parents are always right and political leaders know better' (Shaw 1999). Policymakers in Singapore, however, have recognized the need for science teaching and learning to be driven by inquiry-oriented approaches. In 2008, the science curriculum was reviewed so as to enable students to 'view the pursuit of science as meaningful and useful' by grounding inquiry 'in knowledge, issues and questions that relate to the roles played by science in daily life, society and the environment' (Ministry of Education 2007). There is, therefore, awareness among stakeholders of a need to shift away from the traditional classroom environment where learning activities are largely teacher-directed. The role of students as passive recipients of a static body of knowledge is no longer relevant today; it must be replaced by one where students are active learners who are capable of examining data, forming hypotheses and constructing knowledge that is tentative and subject to scrutiny. There is a need to introduce authenticity in science instruction, in the sense that students must be engaged in work that parallels the work of the professional scientific community.

Despite explicit endorsement of authentic, inquiry-based learning at the systemic level in Singapore, it is still not readily accepted among users at the school level. There are two probable reasons for the existing state of affairs. Firstly, introducing authentic, 
inquiry-based learning in the classroom, in its truest sense, only becomes possible if teachers themselves are skilled in facilitating the inquiry process. This is a challenge because of the tremendous pace of change in Singapore's education system over the past three decades; even young teachers who wish to adopt this approach are faced with the prospect of having to create learning experiences in the classroom very different to the ones they themselves experienced as learners. Secondly, there is a pervasive culture of performativity within Singapore's education system and this will be discussed in greater detail in a later section of this paper. Student performance in high-stakes standardised assessments is inextricably linked to economically advantageous opportunities upon graduation. As Lee (1999) aptly puts it, the Singapore education system appears to be premised upon 'education for earning, not learning'. It is understandable therefore, that tensions arise when attempting to introduce new initiatives into such a system. Teachers and students who have 'learnt to succeed' in the existing system may be resistant to embracing such educational reforms especially when there is no guarantee of achieving similar student outcomes.

This study is undergirded by a social constructivist theoretical framework. At the heart of social constructivism in education is the notion that the 'lived experience' is central to learning (Schwandt 1994). Knowledge is a human construct that is established through the interactions between social actors in a particular context (Au 1998). Using AIBL as an instructional approach, therefore, creates a learning environment in which learners and teachers can engage in generative dialogue about scientific phenomena. As they 'converse, question, explain and negotiate meaning' (Vygotsky 1978) from their observations, they achieve deeper conceptual understanding of the subject matter. Additionally, a number of studies suggest that attitudinal variables play an important role in achieving conceptual change (Eccles, Adler, \& Meece, 1984; Pintrich, Marx \& Boyle, 1993; Wigfield and Eccles 1992). Learners who have high self-efficacy for science learning are more likely to develop conceptual models that are consistent with the larger scientific community.

The current research work seeks to provide empirical evidence of the impact of authentic, inquiry-based learning over traditional instruction on the learning of thermal physics concepts in terms of conceptual understanding, student achievement and student self-efficacy. In addition, it aims to investigate the relationship between students' conceptual understanding and their performance on a standardized achievement test. The study hopes to illuminate the links between pedagogy and learning outcomes in Singapore to determine if they are consistent with findings in the existing literature. In the late 1980s, the Biological Sciences Curriculum Study (BSCS) developed the BSCS 5E Instructional Model to frame the design of inquiry learning in the classroom. The model consists of the following five phases; engagement, exploration, explanation, elaboration and evaluation. In each of these phases, teachers and students engage in activities that allow students to formulate a better understanding of scientific knowledge, attitudes and skills (Bybee et al., 2006). This instructional model has been adopted in this study to guide the design of lesson plans involving authentic, inquiry-based learning. It is hoped that results from this study provide the impetus for future research work in the field of science education in Singapore and the larger Southeast Asian context, beyond thermal physics. 


\section{Literature review}

\section{Conceptual understanding of thermal physics concepts}

The field of thermal physics is one that students interact with on an almost daily basis from very early on in their lives. It is only natural then, that they form rather naive conceptions to explain their observations and experiences well before they encounter it in the formal curriculum in school (Luera, Otto \& Zitzewitz, 2005). These alternative or incomplete conceptions are deep-rooted and common to many students, independent of their age and culture (Yeo and Zadnik 2001).

In Singapore, students are first introduced to scientific concepts about thermal physics in Primary 3 or 4 (aged 9 or 10 years old). However, it is only in secondary school (aged 13 - 16 years old) that they explore these concepts in greater detail (see Appendix 1 for learning outcomes). Unfortunately, difficulties arise when these scientific conceptions being taught in the formal curriculum are not consistent or partially consistent with students' existing conceptions. For example, students tend to relate sensation with temperature; objects that 'feel' cool are often associated with being at a lower temperature (Baser 2006). A strongly held belief such as this can hinder the acceptance of more scientifically accurate conceptions involving thermal equilibrium and the rate of conduction. One of the more interesting findings that emerged from Yeo and Zadnik's (2001) study was that students dissociated 'school science' from 'real-world science'. In other words, their conceptions became context-dependent. They were able to state scientifically accurate concepts to explain phenomena in traditional school settings such as tests and examinations. However, they fell back on their alternative conceptions when presented with the same phenomena in an authentic, real-life scenario.

Hence, for effective teaching and learning to take place, Yeo and Zadnik (2001) argue that traditional instruction is counter-productive; teachers must first encourage students to make their thinking 'explicit through discussions and social interactions' by employing interactive and engaging teaching methods.

\section{Effectiveness of authentic, inquiry-based instruction on the teaching and learning of science}

Science, as a discipline, lends itself quite naturally to the inquiry process. Scientific knowledge is constantly evolving; even as new discoveries are being made, existing 'scientific truths' and concepts are consistently being challenged. Proponents of inquiry-based instruction argue that teaching through inquiry improves student engagement in science learning and promotes deep conceptual learning of scientific concepts because it introduces students to a type of learning that 'parallels the work of practicing scientists' (Capps and Crawford 2013; Hodson 1992). The knowledge constructed by students, individually or collectively, is tentative, subjective and often held up to scrutiny by peers.

One of the key features of authentic instruction is its ability to inform and reinforce student learning. Elements of formative assessment, inherent in authentic instruction, are crucial in developing students' understanding of the subject matter. Yet another essential feature of authentic instruction is its impact on student engagement. A study by Murphy, Lunn, and Jones (2006) on students' engagement in physics highlighted three compelling reasons for leveraging upon authentic instruction in delivering the physics 
curriculum. First, it afforded students the opportunity to really engage with scientific content within relevant social, personal and professional contexts. Second, it shifted students from viewing science as a fixed, unchanging body of knowledge to appreciating the complexity of using this knowledge to make relevant and valid judgments about their environment, and this resonated with the nature of science learning as presented by Capps and Crawford (2013) earlier. Finally, authenticity in science had the potential to 'radically improve career awareness' and in so doing, improve students' motivation to study the subject by making them aware of their 'future relationship with the subject' (p. 245). A clear understanding of the nature of science as a discipline and the potential benefits offered by authentic, inquiry-based instruction make it a viable and attractive alternative to traditional modes of delivery.

\section{The performative culture in Singapore - Help or hindrance?}

Any attempt to reform teaching and learning practices in a system must take into account the existing culture within the system. This section seeks to briefly set in context Singapore's education landscape, with particular attention paid to the issue of performativity. According to Ball (2003), performativity is "a culture and mode of regulation that employs judgments, comparisons and displays as means of incentive, control, attrition and change." In other words, complex social processes and events occurring in a school are reduced to figures, scores, targets or tables of data that may appear 'misleadingly objective and hyper-rational' (Ball 2003). These 'productivity measures' are then often used to support the introduction of new initiatives or justify the continuance of existing practices.

In Singapore's education system, the appraisal processes at the level of both the school as well as the individual teacher, suggest a deeply entrenched culture of performativity. While much autonomy and flexibility is given to school leaders and their management teams in decision making, the state continues to monitor school performance using the School Excellence Model (SEM) introduced in 2000. The SEM is a self-appraisal tool used by a school to score itself in various domains such as leadership, staff management, strategic planning and academic results (Ng 2003). This score is validated by an external team from the Schools Appraisal Board once every 5 years. The validation process is often rigorous and thorough; targets set must be justified and assigned scores must be supported by explicit evidence and documentation that analyse trends over a minimum period of 3 years.

At the level of the individual teacher, performance is appraised using the Enhanced Performance Management System (EPMS), which was introduced in 2001. Over the course of a year, teachers are expected to undergo three Work Review sessions with their reporting officers. In the first Work Review session at the start of the year, targets, expected results and training plans are discussed and recorded. During the second Work Review session conducted in the middle of the year, targets are reviewed, results updated and feedback provided to the teacher on work performance and progress. The final Work Review session at the end of the year, is used to evaluate the teacher's performance for the year as well as capacity for future development. Teachers' performance grade and potential are directly linked to monetary incentives, such as salary increments and performance bonuses, as well as career development opportunities (Liew 2012). 
It is evident therefore, that a high level of accountability is embedded within the structures and processes in Singapore's education system. While schools are allowed and even encouraged to innovate and diversify, the state still maintains central control through the use of monitoring systems within a performative culture ( $\mathrm{Ng}$ 2008). The same may be said at the school level; while teachers are encouraged to explore alternative pedagogies and constantly strive to improve teaching and learning in the classroom, they are still held accountable for producing results and meeting targets set by the school management team. This inherent tension between affording autonomy and maintaining control has the potential to bring about 'unhelpful or indeed damaging practices which nonetheless satisfy performance requirements' (Ball 2003).

\section{Student self-efficacy and science instruction}

Student self-efficacy in science education may be defined as a student's belief in his/her own ability to perform specific scientific tasks or solve specific scientific problems (Cheung 2015). According to Bandura's (1997) social cognitive theory, an individual's selfefficacy is derived from four sources; personal mastery experiences, vicarious learning experiences, social persuasion experiences, and a person's physiological state. Each of these sources is explained briefly below.

- Mastery Experiences (ME). Bandura (1997) postulated that experiences with successful completion of a task should have a strong positive influence on an individual's confidence in his/her ability to complete a similar task. Conversely, failure on a task would have a negative influence on an individual's self-belief.

- Vicarious Learning (VL) Experiences. Vicarious learning experiences occur when an individual watches others performing a task similar to the one they are about to perform. Observing someone else's successes and failures on a task can influence the belief in one's own abilities to perform a similar task.

- Social Persuasion (SP) Experiences. Words of encouragement or social messages can result in an increase in an individual's self-efficacy, thus causing the person to put in extra effort and persist in successfully completing a task. On the other hand, negative social messages also has the potential to undermine one's beliefs about ability.

- Physiological State (PS). Lastly, an individual's physiological state acts as a mediating source working with other sources to amplify or diminish confidence in one's ability to perform a task. Cheerfulness and a positive attitude will have a positive effect of self-efficacy while high levels of stress and anxiety often reduce an individual's confidence in ability (Bandura 1997).

There appears to be a general consensus amongst researchers that student self-efficacy has a positive correlation with student achievement in science (Chen and Pajares 2010; Merchant, Goetz, Keeney-Kennicutt, Kwok, Cifuentes \& Davis, 2012). However, in the particular field of physics education, the literature is still inconclusive. While some researchers have found a strong predictive relationship between student self-efficacy in physics and physics grade (Cavallo, Potter \& Rozman, 2004; Taasoobshirazi \& Sinatra, 
2011), others have reported a negative relationship between physics self-efficacy and physics achievement (Gungor, Eyilmaz \& Fakioglu, 2007). Here again, there appears to be a lack of empirical studies on self-efficacy in physics education in the local context.

Looking specifically at authentic inquiry-based instruction, the literature on the link with students' self-efficacy is similarly inconclusive. Ketelhut (2007), for example, reported that authentic, inquiry-based curriculum in context-specific settings may help raise the self-efficacy of students. On the other hand, Gormally, Brickman, Hallar \& Armstrong (2009) reported that students taught using the inquiry method experienced frustration with the process of 'figuring things out' on their own. These students showed lower gains in self-efficacy after the intervention compared to students taught using traditional methods of instruction. In this particular study, the teachers' practical experience of teaching these students made them realise that the students generally, had a low sense of self-efficacy in physics. While students did make an attempt to solve problems or answer questions, there appeared to be a lack of confidence in their answers, even among those who were able to provide correct responses. The team of teachers believed that employing a different instructional approach could foster a different way of learning and this could, in turn, produce learners with a greater self-efficacy in physics. It is hoped, therefore, that this study would be able to shed some light on how authentic, inquiry-based instruction impacts student self-efficacy in the physics classroom.

\section{Research questions}

This study aims to investigate the following four research questions:

RQ1: What is the impact of authentic, inquiry-based instruction (AIBI) on students' conceptual understanding of thermal physics?

RQ2: What is the impact of authentic, inquiry-based instruction on student achievement in standardised tests?

RQ3: What is the impact of authentic, inquiry-based instruction on students' physics self-efficacy? and.

RQ4: What is the correlation between conceptual understanding of thermal physics and student achievement in standardised tests?

A strong, positive correlation here would suggest that the performative culture that is pervasive throughout our system, does in fact, act as a useful driver of effective teaching and learning. It would not be too farfetched then, to claim that although there is a disproportionate emphasis on meeting targets and producing results, it actually contributes to a deep conceptual understanding of the subject matter being taught. The absence of any such correlation, however, warrants a careful and thorough review of our practices at the systemic level. If significant proportions of our students have a good conceptual understanding of the subject matter but are unable to perform well on achievement tests, it suggests possible flaws in our assessment practices. Existing modes of assessment would be shown to be inadequate in accurately measuring students' subject matter knowledge. 
On the other hand, having a significant proportion of students scoring well in achievement tests despite having poor conceptual understanding of the subject matter would be equally, if not even more, problematic. We would need to carefully examine the effectiveness of existing teaching and learning practices. Such a finding would suggest that the pursuit of 'excellence', as defined by targets and numbers, has inadvertently shifted the emphasis in our system from acquiring knowledge to acquiring results. While subtle and almost imperceptible at the classroom or school level, such a shift would certainly have far-reaching and significant societal implications. We would then be compelled to confront the possibility that the output of our education system may be knowledge deficient and inadequately equipped and this certainly warrants attention and action on the part of educators. At the fundamental level, therefore, we may need to re-examine our aims of education and we must be prepared to embrace reform where necessary.

\section{Methods}

\section{Setting and participants}

This study was conducted in a single secondary school during the course of a regular academic year. In this school, the entire year's curriculum outline, including schemes of work, formal assessment dates and topics covered by each assessment, was communicated to all key stakeholders at the start of the academic year. These stakeholders include students, teachers, middle managers, school leaders and even students' parents. As such, care was taken by the researcher to minimize any disruptions to or resequencing of the planned curriculum. Since this study focused on thermal physics, the subjects selected were limited to students who were learning scientific concepts related to thermal physics at this point in time. In this particular instance, this study involved three classes of Secondary 3 Normal Academic students $(N=89)$. In the year prior to this study, these students had been streamed into these three classes. Students were ranked according to an aggregated score across all subjects before being sorted. Generally, the highest ranked students were sorted into the first class (3 N1) while the lowest ranked students were sorted into the third class $(3 \mathrm{~N} 3)$.

\section{Procedures}

A quasi-experimental pre- and post-test design was employed. For the purpose of this study, students from $3 \mathrm{~N} 2$ were selected to be in the treatment group while students from $3 \mathrm{~N} 1$ and $3 \mathrm{~N} 3$ were selected to be in the control group. The treatment group was taught by the author, while the control groups were taught by colleagues of the author who agreed to be part of the study. All three teachers involved in this study had between 10 and 12 years of teaching experience at the time of the study. Since the students were already streamed according to ability prior to the start of the year, selecting $3 \mathrm{~N} 2$ as the experimental group would allow comparisons to be made with both a high ability and a low ability control group. Although such comparisons are beyond the scope of the current study, it was felt that the data collected here would be useful for future studies in this area.

Lesson plans for both classes were crafted around the same instructional objectives, which were explicitly recorded in the lesson plan documents. Sample lesson plans for both classes have been appended for the readers reference (see Appendix 2). 
In the treatment group, elements of authentic, inquiry-based instruction were incorporated into lesson designs. These included opportunities for student collaboration and discussion, teacher demonstrations, experiments and the use of applets to aid in the visualization of concepts. Where relevant, students were exposed to real-life scenarios where they were required to recognize the concepts learnt and apply their knowledge of thermal physics. Lesson were framed around the 5E Instructional Model developed by the Biological Sciences Curriculum Study (BSCS) which was designed to promote inquiry learning in the classroom. In crafting the detailed lesson plan for this group, each lesson segment was explicitly labelled with its intended stage of inquiry learning.

In the comparison group, students were taught using largely traditional methods of instruction. Teaching and learning activities were teacher-directed and lesson content was delivered using frontal teaching methods. Students were provided with accompanying notes and tasked to complete a set of practice questions at the end of the lesson unit.

\section{Instruments}

Three separate instruments were used in the collection of data so as to adequately address the research questions posed. The first two instruments are both outcome measures but it is worth noting that the focus of each instrument is slightly different.

The first, the Thermal Concept Evaluation (Yeo and Zadnik 2001), is a diagnostic instrument developed based on international research and it was administered to measure changes in students' conceptual understanding of thermal physics. The test reliability, determined using a split-half correlation with Spearman-Brown correction, was 0.81 .

The second, however, is a standardised test that is more specific to the Singapore context and it comprises test items that the students are likely to encounter in their national examinations. This instrument was administered to reflect students' achievement scores and it was incorporated within a termly summative assessment, known as Common Test 2, administered to all three classes in Term 3. Common Test 2 includes assessment items from all topics taught in Term 3. However, for the purpose of this study, only students' scores in assessment items related to thermal physics were extracted for comparison.

The third instrument is a questionnaire developed by researchers to measure students' self-efficacy. The Sources of Self-Efficacy in Science Courses (Physics) Questionnaire (Fencl and Scheel 2005) was administered to measure changes in students' physics self-efficacy before and after the unit of instruction. The questionnaire comprised 33 statements and students were required to select one of the following five responses to these statements; Strongly Disagree, Disagree, Neutral, Agree or Strongly Agree. 19 of these statements were worded positively (eg. I enjoyed physics labs/activities. And I have usually been at ease in this class.) while 14 statements were worded negatively (eg. Physics makes me feel uneasy and confused. And I got really uptight while taking exams/quizzes in this class.) The questionnaire is disaggregated into four subscales by the four sources of self-efficacy described earlier; ME, VL, SP and PS. Internal consistency reliability alpha coefficients range from 0.68 (SP) to 0.88 (PS) with the coefficient for the overall scale at 0.94 (Sawtelle, Brewe \& Kramer, 2012). Numerical ratings from 1 to 5 were 
assigned to each of the five options for the positively worded statements with Strongly Disagree given a rating of 1 and Strongly Agree given a rating of 5. Negatively worded statements were reverse scored with Strongly Disagree given a rating of 5 and Strongly Agree given a rating of 1 .

\section{Results}

This study aimed to investigate the impact of AIBL over traditional physics instruction in terms of both learning and affective student outcomes.

\section{Conceptual understanding}

A pre- and post- concept evaluation test was administered to each of the three classes to determine the effect of the teaching pedagogy on improving students' conceptual understanding. In addition to a comparison of absolute test scores between classes, the learning gains for individual students were also computed. Comparing the raw TCE scores from the pre- and post-tests showed that the mean post-test score $(M=8.46$, $S D=2.88)$ of $\mathrm{N} 2$ students was significantly higher than their mean pre-test score $(M=6.86, S D=2.16), t(27)=4.69, p<.05$. However, the difference in pre- and posttest scores for N1 and N3 students were not statistically significant. A comparison of learning gains showed that the mean normalised learning gain made by $\mathrm{N} 2$ students $(M=0.09, S D=0.10)$ was significantly higher than the mean normalised learning gain made by N3 students $(M=-0.08, S D=0.18), F(2,86)=3.84, p<.05$. However, a similar comparison between the gain scores of N1 and N2 students yielded nonsignificant results.

\section{Student achievement scores}

The achievement test was administered at the end of the entire teaching unit for all classes. The test items used were adopted from those used in previous years' N Level national examinations. Test results showed that the mean achievement score of N1 students $(M=19.88, S D=4.22)$ was significantly higher than the mean achievement score of N2 students $(M=16.32, S D=4.36), F(2,86)=6.27, p=.007$ as well as the mean achievement score of N3 students $(M=16.80, S D=4.32), F(2,86)=6.27$, $p<.05$. There were no significant differences between the mean achievement scores of $\mathrm{N} 2$ and N3 students.

\section{Students' physics self-efficacy}

In terms of affective student outcomes, a comparison between the two groups showed that the post-intervention MRI on the overall self-efficacy scale for N2 students $(M=3.45, S D=0.51)$ was significantly higher than the pre-intervention MRI $(M=3.29, S D=0.48, t(27)=-3.58, p<.01$. However, the difference in pre- and postintervention MRIs for N1 and N3 students were not statistically significant. Results from a further analysis of the four self-efficacy subscales for N2 students are summarised in Table 1. Here again, it is worth noting that the difference in pre- and post-intervention MRIs for N1 and N3 students were not statistically significant for any of the four subscales. 
Table 1 Pre- and post-intervention MRIs for N2 students in the four subscales

\begin{tabular}{|c|c|c|c|c|c|c|}
\hline \multirow[t]{2}{*}{ Subscale } & \multicolumn{2}{|c|}{ Pre-intervention } & \multicolumn{2}{|c|}{ Post-intervention } & \multirow[t]{2}{*}{$t(27)$} & \multirow[t]{2}{*}{$p$-value } \\
\hline & $M$ & $S D$ & $M$ & SD & & \\
\hline ME & 3.23 & 0.56 & 3.39 & 0.55 & -2.25 & $0.033^{*}$ \\
\hline$V L$ & 3.40 & 0.58 & 3.46 & 0.57 & -0.67 & 0.51 \\
\hline SP & 3.32 & 0.44 & 3.54 & 0.47 & -3.33 & $0.003^{* *}$ \\
\hline PS & 3.23 & 0.60 & 3.45 & 0.70 & -2.45 & $0.021^{*}$ \\
\hline
\end{tabular}

*significant at $p<.05$

**significant at $p<.01$

\section{Correlation between student achievement and conceptual understanding}

A Pearson's correlation coefficient was computed to investigate the relationship if any between students' achievement scores on the standardised test and students' scores on the post-intervention conceptual evaluation instrument. In classes where TPI was employed, there was no correlation between students' achievement scores and students' scores on the post-intervention conceptual evaluation instrument. However, in the class where AIBL was employed, there was a positive correlation between students' achievement scores on the standardised test and students' scores on the post-intervention conceptual evaluation instrument $r=0.382, n=28, p<.05$.

\section{Analysis}

This study hoped to illuminate the links between pedagogy and student outcomes in the Singapore context and investigate the correlation, if any, between students' conceptual understanding of thermal physics and their achievement scores in the subject. The findings that emerged are promising and certainly warrant deeper discussion. The gains made by the experimental group in their post-intervention concept evaluation suggest that the use of AIBL is significant in promoting deeper conceptual understanding of thermal physics concepts. The absence of similar results in the comparison group is in agreement with existing literature which states that TPI is ineffective and may even prove counter-productive in the learning of thermal physics.

Interestingly though, achievement scores in the high ability control group (N1 students) were significantly higher than those in the experimental group at the end of the unit of instruction. Yet, the lower ability control group (N3 students) showed no significant difference in achievement scores compared to the experimental group.

Although the intervention in this study was conducted over a period of only 3 weeks, the findings that emerged from the pre- and post-questionnaire on student self-efficacy showed some consistency with existing literature. By the end of the unit of instruction, students in the experimental group reported a significantly greater sense of self-efficacy. Further analysis of the data revealed that three of the four sources of self-efficacy contributed to this increase; ME, SP and PS. SP, in particular, showed a highly significant increase in scores. There appeared to be no significant increase in the subscale for VL.

Yet another interesting finding that emerged was the positive correlation between achievement scores and scores in the post-intervention conceptual evaluation in the experimental group. In the experimental group, students who had scored well on the conceptual evaluation after instruction were also likely to score well on the achievement 
test and the converse was also true. Such a correlation was absent in classes where TPI was employed, suggesting that in these classes, the scores on both tests, which were conducted at the end of the unit of instruction, were somewhat independent of each other.

\section{Discussion}

The mixed effect observed in students' achievement scores could be interpreted in the light of findings by Cobern et al. (2010) which suggested that direct instruction is as good as inquiry-based instruction for traditional outcomes as long as lesson units are soundly designed and good instruction is delivered in both modes. There are a number of other possibilities that could have contributed to such an outcome.

The high ability students had 'learned how to succeed' in the current system. In other words, they had become more adept at test-preparation and test-taking than their peers in N2 and N3. This includes revision methods as well as time and stress management skills during the test itself, so their higher score may not be entirely attributed to deeper conceptual understanding. This is further supported by the lack of correlation between their achievement test scores and their post intervention concept evaluation scores, which will be discussed later on in the paper.

The test items in the achievement test were unable to provide as comprehensive a test of conceptual understanding in thermal physics as the concept evaluation test. While items in the concept evaluation test were well-researched and carefully selected to probe students' overall understanding of thermal physics, test items in the achievement test were directly lifted off previous years' national examination papers so they may have been skewed towards testing particular concepts related to thermal physics. With sufficient practice on the end-of-chapter textbook questions as well as the workbook questions, the high ability students would have learned how to answer such questions without necessarily having achieved deep understanding of the concept.

The significant learning gains made by the $\mathrm{N} 2$ students may not have been sufficient to bridge the pre-existing gap in understanding between the N2 and N1 students. The pre-intervention concept evaluation showed that the N1 students had a significantly higher score than the N2 students. While the N2 students showed significant improvement in conceptual understanding, this improvement could not translate to improved scores. Further study with possible qualitative methods could explore this and other possible reasons for this finding. In all likelihood, though, the difference in achievement scores is due to a combination, rather than any one, of these factors.

As for students' physics self-efficacy, one possible reason for a significant increase in the ME, SP and PS subscales could be the nature of the tasks that were given to students in experimental group. Almost all AIBL lessons involved students participating in collaborative work. Working in groups of four or five, they were given tasks (eg. produce a poster or design a product that would slow down the melting of an ice cream) that necessitated interaction among themselves and with their teacher. This could explain the marked increase in SP scores, as there were ample opportunities for their teacher and peers to positively affirm the work they were engaged in. In addition, the lessons required them to present their products to the class at the end of the lesson and 'defend' their designs against peer/teacher critique. This could have contributed to the increase in ME and PS scores. However, due to the way the lesson was sequenced 
(as evident in the lesson plan in Appendix 2, all students in the class worked concurrently and there was little opportunity for them to observe one another at work. While they saw the final product designed by their peers during the student presentations at the end of the lesson, they were unable to observe their peers during the designing process. Neither were they shown any teacher demonstrations or suggested techniques on how to go about completing the task. These, together with the fact that they were already engaged in their own activities during the lesson meant that there was hardly any opportunity for vicarious learning to take place. Hence, the VL scores showed no significant increase by the end of the unit of instruction. These claims are of course, tentative and must be substantiated with deeper investigations and more extensive research. What is more certain from this study, at least, is that traditional instruction in thermal physics has little impact, if any at all, on students' beliefs in their own ability to perform scientific tasks related to thermal physics.

Findings from the correlational study seem to suggest that when AIBL is employed as an instructional approach, it is more likely that achievement scores are accurate predictors of students' conceptual understanding. Conversely, the absence of any correlation between conceptual understanding and student achievement in the TPI classrooms also imply that when traditional instruction is employed, scores on achievement tests may not be accurate predictors of student understanding of the subject matter. This, in turn, has serious implications especially in a system where achievement scores are often depended upon for key decision-making processes in school such as student ranking, streaming or course admission.

\section{Limitations and future work}

As with all research studies, there are a number of limitations that must be considered when interpreting the findings from this study. For the purpose of brevity however, three of the main limitations will be discussed here. This is the followed by a brief discussion on possible areas for future research. Firstly, the unit of instruction was carried out over a period of only 3 weeks, which may be too short a time for significant changes to be measured or even observed. Attitudes, motivation and self-efficacy are deeply entrenched within individuals and any attempt to measure changes in these areas requires a significant investment of time. This possibly explains why students in the experimental group only showed favourably significant differences in four out of the 33 items on the self-efficacy instrument. In terms of conceptual understanding of science content, there is sufficient evidence in the existing literature to suggest that learning gains have a cumulative effect and they become more significant when the intervention is carried out over several years (Lee, Buxton, Lewis \& LeRoy, 2006).

Secondly, this study investigated the impact of AIBL in the teaching and learning of thermal physics. Hence, there is a need to be cautious when extrapolating such findings to the broader field of physics or even science in general. While the findings here are generally consistent with existing literature in the field of science education, more research is required to verify if similar outcomes arise in the teaching and learning of other domains of science.

Thirdly, it is worth noting that this study was conducted with students in a secondary school during a regular school term. Students remained within three intact classes to 
minimise disruption to the students as well as the broader school curriculum. While all three classes did not receive any prior instruction on thermal physics, the TCE pre-test administered at the start of the study showed that there were, in fact, initial group differences. The students in N1 showed significantly higher pre-test scores than their peers in N2 and N3. This was mitigated somewhat by comparing normalised learning gains after administering the TCE post-test to all three groups, rather than simply comparing their absolute gain in scores.

Having said that, this study has still provided the researcher with some valuable insights and illuminated at least one area for further research. A comparison of the learning gains made in all three classes showed that there was a significant difference in learning gains between the experimental group and the low-ability control group. However, there was no such difference between the experimental group and the high-ability control group. This seems to suggest that the impact of AIBL may not be uniform across all learner profiles. Further research is required to investigate how students of different ability respond to AIBL in the learning of thermal physics concepts. While interesting, this is certainly not unexpected - a previous study by Cuevas, Lee, Hart, and Deaktor (2005) showed that inquiry instruction does indeed yield greater increases in achievement for low-achieving, low-SES at risk students. Whether or not such a finding is applicable to our local context is uncertain and presents us with an opportunity for future research.

\section{Conclusion}

If we are concerned about continually enhancing the learning experience of our students, then we must examine how teachers seek to improve their practice. Action research offers us a viable and systematic way of achieving such improvements. Engaging in action research would certainly add on to the deluge of teaching and nonteaching responsibilities that teachers are already expected to attend to. However, it is worth reminding ourselves that teachers are in the unique position of being curriculum gatekeepers. From design to enactment, the influence that teachers have on the learning experiences that students encounter in the classrooms cannot be over-emphasised. We must, therefore, endeavour to shift engagement in action research from being an optional or recommended activity to being one that is an essential component of teachers' work in schools. Teaching practice, informed by context-relevant research, is bound to advance science education in the classroom. The support provided by MOE and the school leadership, in terms of (1) deliberately structuring time and space for action research to take place in schools, and (2) developing among teaching staff, a school-wide culture of using action research to improve practice, is vital to the success of such a shift.

There is also a need to re-look at our assessment practices and the manner in which data is used. Assessment must be designed to inform the teaching and learning process; ideally, it should provide accurate feedback to both teachers and learners about the learners' understanding of the subject being taught. This, in turn, provides direction for the next phase of the teaching and learning process. In a system that is centred on principles of meritocracy and heavily reliant upon assessment data for ability grouping from a very young age, it is imperative that such data represents a true reflection of learner understanding. This becomes especially important when the decision making that follows the analysis of such assessment data often have significant long term effects 
on the learners in terms of courses made available to them and their subsequent job prospects upon exiting the system.

While educators in Singapore have come a long way in embracing alternative pedagogies and exploring new ways of teaching and learning, it is not too farfetched to claim that traditional forms of instruction continue to be employed quite extensively in schools. It is worrying therefore when empirical studies such as this one show the absence of any correlation between student achievement and conceptual understanding of the subject. In our push towards achieving academic excellence, are we inadvertently producing 'good test-takers', rather than 'good learners'? Is the assumption that the two are always synonymous a valid one? For a system that has experienced such tremendous change over the past three decades, it is odd that our assessment landscape continues to remain largely dormant. If we are willing to reframe our understanding of how learning takes place, then we must be prepared to relook at our existing assessment practices. More weight should be given to authentic and formative assessment embedded within the curriculum, rather than periodic, standardised tests which are typically conducted at the end of a unit of instruction. Ideally, though, if we shift the spotlight onto learning for understanding, rather than learning for grading, we might see a change in the type of learner our system produces and there may be less of a need to rely so heavily on such assessment data.

\section{Appendix 1: Thermal Physics learning outcomes in the formal curriculum}

Table 2

\begin{tabular}{ll}
\hline Level & Learning Outcomes \\
\hline Primary 3 and Primary 4 & By the end of this unit, students should be able to: \\
- List some common sources of heat. \\
- State that the temperature of an object is a measurement of its degree \\
of hotness. \\
- Differentiate between heat and temperature. - heat is a form of \\
energy - temperature is a measurement of the degree of hotness of an \\
object \\
- Show an understanding that heat flows from a hotter to a colder \\
object/region/place until both reach the same temperature. \\
- Relate the change in temperature of an object to the gain or loss of \\
heat by the object. \\
- List some effects of heat gain/loss in our everyday life. - contraction/ \\
expansion of objects (solid, liquid and gas) - change in state of matter \\
- Identify good and poor conductors of heat. - good conductors: \\
metals - poor conductors: wood, plastics, air \\
By the end of this unit, students should be able to: \\
- Describe some effects and applications of expansion and contraction \\
in everyday life State the S.l. unit of temperature and use the \\
appropriate unit for it \\
- Explain what is meant by conduction, convection and radiation \\
- Identify and explain applications of heat conduction and convection \\
(e.g. in cooling, heating and insulation) \\
- Show an understanding that the rate of heat loss or gain by a body \\
through radiation is affected by the (i) nature of its surface and (ii) \\
temperature difference between the body and its surroundings \\
- Identify and explain applications of heat radiation (e.g. radiant heaters, \\
solar radiation)
\end{tabular}


Table 2 (Continued)

\begin{tabular}{ll}
\hline Secondary 3 and Secondary 4 & Kinetic Model of Matter \\
(aged $15-16$ years old) & Compare the properties of solids, liquids and gases \\
- Describe qualitatively the molecular structure of solids, liquids and \\
gases, relating their properties to the forces and distances between \\
molecules and to the motion of the molecules \\
- Describe the relationship between the motion of molecules and \\
temperature \\
Transfer of Thermal Energy \\
- Show understanding that thermal energy is transferred from a region \\
of higher temperature to a region of lower temperature \\
- Describe, in molecular terms, how energy transfer occurs in solids \\
- Describe, in terms of density changes, convection in fluids \\
material medium and the rate of energy transfer is affected by: \\
i. colour and texture of the surface \\
ii. surface temperature \\
iii. surface area \\
- Apply the concept of thermal energy transfer to everyday applications \\
Thermal Properties of Matter \\
- Describe a rise in temperature of a body in terms of an increase in its \\
internal energy (random thermal energy) \\
- Describe melting/solidification and boiling/condensation as processes \\
of energy transfer without a change in temperature \\
- Explain the difference between boiling and evaporation \\
\end{tabular}

\section{Appendix 2: Lesson Plans (AIBL vs TPI)}

Lesson Plan - Set 2

Topic: Transfer of Thermal Energy.

Lesson Duration: 1 h 30 min.

Instructional objectives:

By the end of this lesson, students should be able to

- Understand that that thermal energy is transferred from a region of higher temperature to a region of lower temperature

- Describe in molecular terms the process of conduction

- Describe in terms of density changes, convection in fluids

- Explain energy transfer by radiation

\section{Prior knowledge:}

Prior to this lesson, students should be able to

- state that heat is a form of energy

- understand that a medium refers to an environment

\section{AIBL Detailed Lesson Plan}

Day/Date: Friday, 31 July 2015.

Class/Venue: 3 N2/Classroom.

\section{Resources:}

- Laptop and projector

- Workbook

- Raw materials for ice cream project (black paper, foil, cloth, Styrofoam, plastic container) $\times 10$ sets 
Table 3

\begin{tabular}{|c|c|c|c|c|c|}
\hline $\mathrm{S} / \mathrm{N}$ & Time & Teaching/Learning Activity & Resources & IBL stage & Rationale/Remarks \\
\hline \multirow[t]{2}{*}{1.} & \multirow[t]{2}{*}{$10 \mathrm{~min}$} & $\begin{array}{l}\text { Introduction: } \\
\text { Brief students on lesson } \\
\text { outline }\end{array}$ & - & - & \multirow[t]{4}{*}{$\begin{array}{l}\text { To elicit students' prior } \\
\text { knowledge and situate } \\
\text { them within the topic. }\end{array}$} \\
\hline & & $\begin{array}{l}\text { Explain that thermal } \\
\text { energy is a form of energy } \\
\text { that can be transferred. } \\
\text { Recall methods of heat } \\
\text { transfer from lower sec } \\
\text { science. }\end{array}$ & & \multirow[t]{3}{*}{ Evaluate } & \\
\hline \multirow[t]{6}{*}{2.} & \multirow[t]{6}{*}{$15 \min$} & Lesson Development & & & \\
\hline & & $\begin{array}{l}\text { Key Concept - Thermal } \\
\text { Equilibrium }\end{array}$ & & & \\
\hline & & $\begin{array}{l}\text { Q: What happens to a cup } \\
\text { of hot water left to stand } \\
\text { for a few hours in a room? } \\
\text { And } \\
\text { Q: What happens to a cup } \\
\text { of cold water left to stand } \\
\text { for a few hours in a room? }\end{array}$ & & ENGAGE & $\begin{array}{l}\text { Students must be able to } \\
\text { differentiate between } \\
\text { 'energy', 'sensation' and } \\
\text { 'temperature'. }\end{array}$ \\
\hline & & $\begin{array}{l}\text { Link 'sensation 'to the } \\
\text { transfer of energy into or } \\
\text { out of our hands. Use } \\
\text { example of a cup of hot } \\
\text { coffee or a metal } \\
\text { doorknob. }\end{array}$ & $\begin{array}{l}\text { Iced water, room } \\
\text { temperature water and hot } \\
\text { water }\left(70{ }^{\circ} \mathrm{C}\right)\end{array}$ & EXPLORE & $\begin{array}{l}\text { Students must understand } \\
\text { that thermal energy } \\
\text { transfer will stop when } \\
\text { objects reach the same } \\
\text { temperature. }\end{array}$ \\
\hline & & $\begin{array}{l}\text { Student Demo: } 3 \text { water } \\
\text { troughs }\end{array}$ & & & \\
\hline & & $\begin{array}{l}\text { Q: When does energy } \\
\text { transfer stop? }\end{array}$ & & & \\
\hline \multirow[t]{7}{*}{3.} & \multirow[t]{7}{*}{$15 \mathrm{~min}$} & Lesson Development & - & & \\
\hline & & $\begin{array}{l}\text { Key concept - Methods of } \\
\text { Heat Transfer }\end{array}$ & & \multirow[t]{6}{*}{ EXPLAIN } & \multirow{6}{*}{$\begin{array}{l}\text { Students already have } \\
\text { some understanding of } \\
\text { the concepts involved } \\
\text { with conduction, } \\
\text { convection and radiation } \\
\text { so it was important to get } \\
\text { them to elicit and } \\
\text { reinforce prior concepts } \\
\text { learnt. }\end{array}$} \\
\hline & & $\begin{array}{l}\text { Conduction } \\
\text { - fastest in solids, slowest } \\
\text { in gases } \\
\text { - presence of free electrons } \\
\text { in metals }\end{array}$ & & & \\
\hline & & $\begin{array}{l}\text { Convection } \\
\text { - Density changes in a } \\
\text { fluid } \\
\text { - Causes movement of } \\
\text { medium }\end{array}$ & & & \\
\hline & & $\begin{array}{l}\text { Radiation } \\
\text { - Features of good } \\
\text { absorbers/radiators } \\
\text { - Features of poor }\end{array}$ & & & \\
\hline & & - absorbers/radiators & & & \\
\hline & & $\begin{array}{l}\text { Student Demo: } \\
\text { Get a row of students to } \\
\text { act as particles in a } \\
\text { medium and demonstrate } \\
\text { how energy is transferred } \\
\text { from one end to another. }\end{array}$ & & & \\
\hline 4. & $5 \min$ & $\begin{array}{l}\text { Briefing in Ice Cream } \\
\text { Challenge, Movement to } \\
\text { Physics laboratory }\end{array}$ & Laptop, projector & & \\
\hline
\end{tabular}


Table 3 (Continued)

\begin{tabular}{|c|c|c|c|c|c|}
\hline \multirow[t]{2}{*}{5.} & \multirow[t]{2}{*}{$30 \mathrm{~min}$} & \multicolumn{4}{|l|}{$\begin{array}{l}\text { Group Activity: Ice Cream } \\
\text { Challenge }\end{array}$} \\
\hline & & $\begin{array}{l}\text { Students will be tasked } \\
\text { with designing a 'fridge' in } \\
\text { order to prevent a popsicle } \\
\text { from melting. They work in } \\
\text { groups of } 4 \text { and are } \\
\text { provided with a set of } \\
\text { materials. They are also } \\
\text { expected to produce a } \\
\text { sketch of their design with } \\
\text { explanations for their } \\
\text { choice of materials. }\end{array}$ & $\begin{array}{l}\text { Black paper, Aluminium } \\
\text { foil, stryrofoam, sponge, } \\
\text { cotton, Ziploc bags, plastic } \\
\text { container, Sketch book, } \\
\text { markers }\end{array}$ & $\begin{array}{l}\text { ENGAGE/ } \\
\text { EXPLORE/ } \\
\text { EVALUATE }\end{array}$ & $\begin{array}{l}\text { As students collaborate } \\
\text { and discuss ideas, they will } \\
\text { learn from one another } \\
\text { and get a chance to } \\
\text { verbalise their own } \\
\text { thoughts. }\end{array}$ \\
\hline \multirow[t]{3}{*}{6.} & \multirow[t]{3}{*}{$10 \mathrm{~min}$} & $\begin{array}{l}\text { Student Presentations \& } \\
\text { Discussions }\end{array}$ & - & & \\
\hline & & \multirow{2}{*}{$\begin{array}{l}\text { Two groups of students } \\
\text { will be selected to present } \\
\text { their designs to the class } \\
\text { and explain their choices. } \\
\text { Students will be invited to } \\
\text { discuss about the merits } \\
\text { and disadvantages of } \\
\text { certain materials. }\end{array}$} & & EXPLAIN & $\begin{array}{l}\text { To allow students to make } \\
\text { their thinking explicit and } \\
\text { share ideas with one } \\
\text { another. }\end{array}$ \\
\hline & & & & & $\begin{array}{l}\text { A conscious effort was } \\
\text { made to allow the lesson } \\
\text { to be as student-directed } \\
\text { as possible. }\end{array}$ \\
\hline \multirow[t]{2}{*}{7.} & \multirow[t]{2}{*}{$5 \mathrm{~min}$} & Conclusion & - & - & \\
\hline & & $\begin{array}{l}\text { Recap of main ideas and } \\
\text { key learning points by } \\
\text { teacher. }\end{array}$ & & & \\
\hline
\end{tabular}

\section{TPI Detailed Lesson Plan}

Day/Date: Tuesday, 28 July 2015; Thursday, 30 July 2015.

Class/Venue: 3 N1/Classroom, 3 N3/Classroom.

\section{Resources:}

\section{- Laptop and projector \\ - Workbook \\ - Handouts \\ - PowerPoint Presentation}

Table 4

\begin{tabular}{|c|c|c|c|c|}
\hline $\mathrm{S} / \mathrm{N}$ & Time & Teaching/Learning Activity & Resources & Rationale/Remarks \\
\hline \multirow[t]{3}{*}{1.} & \multirow[t]{3}{*}{$5 \min$} & Introduction: & \multirow{5}{*}{$\begin{array}{l}\text { PowerPoint } \\
\text { slides }\end{array}$} & \multirow{5}{*}{$\begin{array}{l}\text { To elicit students' prior knowledge } \\
\text { and situate them within the topic. }\end{array}$} \\
\hline & & Brief students on lesson outline & & \\
\hline & & $\begin{array}{l}\text { Explain that thermal energy is a form of } \\
\text { energy that can be transferred. Recall } \\
\text { methods of heat transfer from lower sec } \\
\text { science. }\end{array}$ & & \\
\hline \multirow[t]{3}{*}{2.} & \multirow[t]{3}{*}{$15 \min$} & Lesson Development & & \\
\hline & & Conduction & & \\
\hline & & $\begin{array}{l}\text { Teacher explains the mechanism of } \\
\text { conduction using the prepared slides } \\
\text { covering conduction in solids, liquids and } \\
\text { gases. This is followed by an explanation of } \\
\text { how the presence of free electrons in } \\
\text { metals speed up the rate of conduction }\end{array}$ & $\begin{array}{l}\text { PowerPoint } \\
\text { slides }\end{array}$ & $\begin{array}{l}\text { A deliberate teacher directed } \\
\text { approach adopted. }\end{array}$ \\
\hline
\end{tabular}


Table 4 (Continued)

\begin{tabular}{|c|c|c|c|c|}
\hline \multirow[t]{2}{*}{3.} & \multirow[t]{2}{*}{$10 \mathrm{~min}$} & Handout 1 - Conduction & \multirow[t]{2}{*}{ Handout 1} & \multirow{2}{*}{$\begin{array}{l}\text { This is to allow students some time } \\
\text { to consolidate the information } \\
\text { provided by the teacher. }\end{array}$} \\
\hline & & $\begin{array}{l}\text { Students are given some time to complete } \\
\text { the handout on the main points involved } \\
\text { with conduction }\end{array}$ & & \\
\hline \multirow[t]{2}{*}{5.} & \multirow[t]{2}{*}{$15 \mathrm{~min}$} & Convection & \multirow{2}{*}{$\begin{array}{l}\text { PowerPoint } \\
\text { slides }\end{array}$} & \multirow{2}{*}{$\begin{array}{l}\text { A deliberate teacher directed } \\
\text { approach adopted. }\end{array}$} \\
\hline & & $\begin{array}{l}\text { Teacher explains the mechanism of } \\
\text { convection using the prepared slides. } \\
\text { Teacher then goes through examples to } \\
\text { show how convection occurs in various } \\
\text { applications. }\end{array}$ & & \\
\hline \multirow[t]{2}{*}{6.} & \multirow[t]{2}{*}{$10 \mathrm{~min}$} & Handout 2 - Convection & \multirow[t]{3}{*}{ Handout 2} & \multirow{2}{*}{$\begin{array}{l}\text { This is to allow students some time } \\
\text { to consolidate the information } \\
\text { provided by the teacher. }\end{array}$} \\
\hline & & $\begin{array}{l}\text { Students are given some time to complete } \\
\text { the handout on the main points involved } \\
\text { with convection. }\end{array}$ & & \\
\hline \multirow[t]{2}{*}{7.} & \multirow[t]{2}{*}{$15 \mathrm{~min}$} & Radiation & & \\
\hline & & $\begin{array}{l}\text { Teacher explains the mechanism of } \\
\text { radiation using the prepared slides. Teacher } \\
\text { then goes through characteristics of good } \\
\text { absorbers/radiators. }\end{array}$ & $\begin{array}{l}\text { PowerPoint } \\
\text { slides }\end{array}$ & $\begin{array}{l}\text { A deliberate teacher directed } \\
\text { approach adopted. }\end{array}$ \\
\hline \multirow[t]{2}{*}{8.} & \multirow[t]{2}{*}{$10 \mathrm{~min}$} & Handout 3 - Radiation & \multirow[t]{3}{*}{ Handout 3} & \multirow{2}{*}{$\begin{array}{l}\text { This is to allow students some time } \\
\text { to consolidate the information } \\
\text { provided by the teacher. }\end{array}$} \\
\hline & & $\begin{array}{l}\text { Students are given some time to complete } \\
\text { the handout on the main points involved } \\
\text { with radiation. }\end{array}$ & & \\
\hline \multirow[t]{2}{*}{9.} & \multirow[t]{2}{*}{$5 \mathrm{~min}$} & Applications & & \\
\hline & & $\begin{array}{l}\text { Teacher goes through some applications } \\
\text { that make use of thermal energy transfer } \\
\text { eg. Thermos flask, food packaging etc. }\end{array}$ & \multirow[t]{2}{*}{$\begin{array}{l}\text { PowerPoint } \\
\text { slides }\end{array}$} & \multirow[t]{2}{*}{$\begin{array}{l}\text { To help students understand how } \\
\text { thermal energy transfer may be } \\
\text { applied to real-life situations. }\end{array}$} \\
\hline \multirow[t]{2}{*}{10.} & \multirow[t]{2}{*}{$5 \mathrm{~min}$} & Conclusion & & \\
\hline & & $\begin{array}{l}\text { Recap of main ideas and key learning } \\
\text { points by teacher. }\end{array}$ & $\begin{array}{l}\text { PowerPoint } \\
\text { slides }\end{array}$ & $\begin{array}{l}\text { To recap the lesson and highlight } \\
\text { the key concepts learnt. }\end{array}$ \\
\hline
\end{tabular}

\section{Acknowledgements}

This manuscript is based on work carried out in a Singapore Ministry of Education (MOE) secondary school. The opinions or findings presented are those of the author and do not necessarily reflect those of the National Institute of Education or MOE. The author wishes to recognize the assistance of Mr. Aaron Cheng, Mr. Jerry Tai and Mr. Ernest Ng, secondary school physics teachers, for their contributions towards this work.

\section{Author's information}

Flavian B. Fernandez serves as the Subject Head (Physics) in Woodgrove Secondary School, Singapore. He has been teaching physics for the past 10 years and currently leads a team of physics teachers in enhancing the physics curriculum in the school. He completed his Masters in Education (Curriculum and Teaching) from the National Institute of Education, Singapore.

\section{Competing interests}

The author declares that he has no competing interests.

Received: 2 February 2017 Accepted: 29 June 2017

Published online: 28 July 2017

\section{References}

Au, K. H. (1998). Social constructivism and the school literacy learning of students of diverse backgrounds. Journal of Literacy Research, 30(2), 297-319.

Ball, S. J. (2003). The teacher's soul and the terrors of performativity. Journal of Education Policy, 18(2), 215-228.

Bandura, A. (1997). In S. F. Brennan \& C. Hastings (Eds.), Self-efficacy: The exercise of control. New York, NY: W.H. Freeman and Company.

Baser, M. (2006). Fostering conceptual change by cognitive conflict based instruction on students' understanding of heat and temperature concepts.Eurasia. Journal of Mathematics, Science and Technology Education, 2(2), 96-114.

Bouillion, L. M., \& Gomez, L. M. (2001). Connecting school and community with science learning: Real-world problems and school-community partnerships as contextual scaffolds. Journal of Research in Science Teaching, 38, 878-898. 
Bybee, R. W., Taylor, J. A., Gardner, A., Van Scotter, P., Powell, J. C., Westbrook, A., \& Landes, N. (2006). The BSCS $5 E$ instructional model: Origins and effectiveness. Colorado Springs: BSCS, 5, 88-98.

Capps, D. K., \& Crawford, B. A. (2013). Inquiry-based instruction and teaching about nature of science: Are they happening? Journal of Science Teacher Education, 24(3), 497-526.

Carey, S. (2000). Science education as conceptual change. Journal of Applied Developmental Psychology, 21(1), 13-19.

Cavallo, A. M., Potter, W. H., \& Rozman, M. (2004). Gender differences in learning constructs, shifts in learning constructs, and their relationship to course achievement in a structured inquiry, yearlong college physics course for life science majors. School Science and Mathematics, 104(6), 288-300.

Chen, J. A., \& Pajares, F. (2010). Implicit theories of ability of grade 6 science students: Relation to epistemological beliefs and academic motivation and achievement in science. Contemporary Educational Psychology, 35(1), 75-87.

Cheung, D. (2015). The combined effects of classroom teaching and learning strategy use on students' chemistry selfefficacy. Research in Science Education, 45(1), 101-116.

Cobern, W. W., Schuster, D., Adams, B., Applegate, B., Skjold, B., Undreiu, A., et al. (2010). Experimental comparison of inquiry and direct instruction in science. Research in Science \& Technological Education, 28(1), 81-96.

Cuevas, P., Lee, O., Hart, J., \& Deaktor, R. (2005). Improving science inquiry with elementary students of diverse backgrounds. Journal of Research in Science Teaching, 42(3), 337-357.

Eccles, J., Adler, T., \& Meece, J. (1984). Sex differences in achievement: A test of alternate theories. Journal of Personality and Social Psychology, 46, 26-43.

Fencl, H., \& Scheel, K. (2005). Engaging students: And examination of the effects of teaching strategies on self-efficacy and course climate in a nonmajors physics course. Journal of College Science Teaching, 35(1), 20-24.

Fortus, D., Dershimer, R. C., Krajcik, J., Marx, R. W., \& Mamlok-Naaman, R. (2004). Design-based science and student learning. Journal of Research in Science Teaching, 41(10), 1081-1110.

Glanz, J. (2014). Action research: An educational leader's guide to school improvement. Rowman \& Littlefield.

Gormally, C., Brickman, P., Hallar, B., \& Armstrong, N. (2009). Effects of inquiry-based learning on students' science literacy skills and confidence. International journal for the scholarship of teaching and learning, 3(2), 16.

Gungor, A. A., Eryilmaz, A., \& Fakioglu, T. (2007). The relationship of freshmen's physics achievement and their related affective characteristics. Journal of Research in Science Teaching, 44(8), 1036-1056.

Hallinger, P. (2010). Making education reform happen: Is there an 'Asian'way? School Leadership and Management, 30(5), 401-418.

Hmelo, C. E., Holton, D. L., \& Kolodner, J. L. (2000). Designing to learn about complex systems. The Journal of the Learning Sciences, 9(3), 247-298.

Hodson, D. (1992). In search of a meaningful relationship: An exploration of some issues relating to integration in science and science education. International Journal of Science Education, 14(5), 541-562.

Ketelhut, D. J. (2007). The impact of student self-efficacy on scientific inquiry skills: An exploratory investigation in River City, a multi-user virtual environment. Journal of Science Education and Technology, 16(1), 99-111.

Lee, W. O. (1999). Social change and education problems in Japan, Singapore and Hong Kong. London: Macmillan.

Lee, O., Buxton, C., Lewis, S., \& LeRoy, K. (2006). Science inquiry and student diversity: Enhanced abilities and continuing difficulties after an instructional intervention. Journal of Research in Science Teaching, 43(7), 607-636.

Liew, W. M. (2012). Perform or else: The performative enhancement of teacher professionalism. Asia Pacific Journal of Education, 32(3), 285-303.

Luera, G. R., Otto, C. A., \& Zitzewitz, P. W. (2005). A conceptual change approach to teaching energy and thermodynamics to pre-service elementary teachers. Journal of Physics Teacher Education Online, 2(4), 3-8.

McNiff, J. (2013). Action research: Principles and practice. Routledge.

Merchant, Z., Goetz, E. T., Keeney-Kennicutt, W., Kwok, O. M., Cifuentes, L., \& Davis, T. J. (2012). The learner characteristics, features of desktop 3D virtual reality environments, and college chemistry instruction: A structural equation modeling analysis. Computers \& Education, 59(2), 551-568.

Ministry of Education. (2007). Primary science syllabus. Singapore: Author.

Murphy, P., Lunn, S., \& Jones, H. (2006). The impact of authentic learning on students' engagement with physics. The Curriculum Journal, 17(3), 229-246.

Ng, P. T. (2003). The Singapore school and the school excellence model. Educational Research for Policy and Practice, 2(1), 27-39.

Ng, P. T. (2008). Thinking schools, learning nation, Thinking schools, learning nation: Contemporary issues and challenges (pp. 1-6).

Pintrich, P. R., Marx, R. W., \& Boyle, R. A. (1993). Beyond cold conceptual change: The role of motivational beliefs and classroom contextual factors in the process of conceptual change. Review of Educational Research, 63(2), 167-199.

Salleh, H. (revised for resubmission). Action research in Singapore: Where are we now? Asia-Pacific Science Education.

Sawtelle, V., Brewe, E., \& Kramer, L. H. (2012). Exploring the relationship between self-efficacy and retention in introductory physics. Journal of Research in Science Teaching, 49(9), 1096-1121.

Schwandt, T. A. (1994). Constructivist, interpretivist approaches to human inquiry.

Shaw, S. M. (1999). It's true. Asians can't think. Time, may, 31, 23.

Taasoobshirazi, G., \& Sinatra, G. M. (2011). A structural equation model of conceptual change in physics. Journal of Research in Science Teaching, 48(8), 901-918.

Vygotsky, L. S. (1978). Mind in society: The development of higher mental processes. Cambridge: Harvard University Press.

Warren, B., Ballenger, C., Ogonowski, M., Rosebury, A., \& Hudicourt-Barnes, J. (2001). Rethinking diversity in teaching science: The logic of everyday sense-making. Journal of Research in Science Teaching, 38, 529-552.

Wigfield, A., \& Eccles, J. (1992). The development of achievement task values: A theoretical analysis. Developmental Review, 12, 265-310.

Yeo, S., \& Zadnik, M. (2001). Introductory thermal concept evaluation: Assessing students' understanding. The Physics Teacher, 39(8), 496-504. 